\title{
ANALISA KEANDALAN MESIN SCREW PRESS BERDASARKAN IDENTIFIKASI KEGAGALAN FAILURE MODE AND EFFECT ANALYSIS DAN ROOT CAUSE ANALYSIS
}

\author{
Syamsuddin Nur ${ }^{*}$, Ikhwansyah Isranuri ${ }^{2}$ \\ Departemen Teknik Mesin, Fakultas Teknik, Universitas Sumatera Utara \\ Jalan Dr. T. Mansyur No. 9, Padang Bulan, Kec. Medan Baru, Kota Medan, Sumatera Utara 20222, Indonesia \\ *Email: syamsuddinnur.sn@gmail.com
}

\begin{abstract}
ABSTRAK
Mesin screw press pada pabrik kelapa sawit berfungsi untuk memisahkan minyak dari buah lunak dan mengepressnya untuk menghasilkan crude oil dan nut. Pada PT. Samudera Sawit Nabati memiliki mesin screw press yang sistem perawatannya kurang maksimal. Tujuan penelitian ini adalah untuk mengetahui nilai keandalan dari mesin screw press dengan metode Reliability Block Diagram (RBD) berdasarkan identifikasi kegagalan menggunakan Failure Mode and Effect Analysis (FMEA) dan Root Cause Analysis (RCA). Berdasarkan identifikasi kegagalan metode FMEA, didapat komponen kritis pada mesin screw press yaitu thrust bearing, roller bearing dan oil seal dengan masing-masing nilai RPN sebesar 240, 240, dan 210. Pada analisa menggunakan metode RCA terdapat empat kategori yang menjadi penyebab kegagalan yaitu manusia, mesin, metode, dan lingkungan. Kemudian nilai keandalan mesin screw press menggunakan RBD pada penelitian ini didapat sebesar $79,49 \%$ pada 50 jam operasi.
\end{abstract}

Kata kunci: Screw Press, Pemeliharaan, Kegagalan, Keandalan

\begin{abstract}
The screw press machine in the palm oil mill functions to separate the oil from the soft fruit and presses it to produce crude oil and nuts. At PT. Samudera Sawit Nabati has a screw press machine whose maintenance system is not optimal. The purpose of this study was to determine the reliability value of the screw press machine with Reliability Block Diagram based on failure identification using Failure Mode and Effect Analysis and Root Cause Analysis. Based on FMEA, the critical components of the screw press machine were obtained, namely thrust bearings, roller bearings and oil seals with RPN values of 240, 240, and 210 respectively. In the analysis using RCA, there were four categories that caused the failure, namely humans, machines, methods, and environment. Then the reliability value of the screw press machine using RBD in this study was obtained at $79.49 \%$ at 50 hours of operation.
\end{abstract}

Keywords: Screw Press, Maintenance, Failure, Reliability

\section{PENDAHULUAN}

Pengolahan buah kelapa sawit menjadi minyak sawit dilakukan dengan menggunakan mesin-mesin produksi seperti sterilizer, thereser, digester, screw press, vibrating screen, continous clarifier, oil tank, oil purifier, vacumm drier, dan storage tank. Salah satu peralatan yang berperan penting untuk menghasilkan minyak kelapa sawit adalah screw press. Alat ini berfungsi untuk memeras daging buah kelapa sawit yang telah direbus dan menghasilkan minyak kelapa sawit yang masih kasar yang disebut crude oil (CO). ${ }^{[1]}$

Dikarenakan masih sering terjadi kerusakan pada mesin screw press, sehingga perlu dilakukan analisa terhadap faktor-faktor yang dominan dalam kerugian yang diakibatkan oleh kerusakan mesin dan melakukan analisa terhadap penyebab besarnya kontribusi faktor - faktor tersebut untuk menjadi masukan dalam penerapan total productive maintenance. Penelitian ini dilakukan di bagian stasiun kempa yaitu pada mesin screw press untuk mengetahui nilai keandalan dari mesin tersebut dengan metode Reliability Block Diagram (RBD) berdasarkan identifikasi penyebab-penyebab kegagalan yang terjadi menggunakan Failure Mode Effect and Analysis (FMEA), dan Root Cause Analysis (RCA). 


\section{TEORI}

Pemeliharaan

Pemeliharaan (Maintenace) adalah kegiatan untuk memelihara atau menjaga fasilitas atau peralatan pabrik dan mengadakan perbaikan atau penggantian yang diperlukan agar supaya terdapat suatu keadaaan operasi produksi yang memuaskan sesuai dengan apa yang direncanakan, maka fasilitas dapat digunakan untuk proses produksi atau sebelum jangka waktu yang direncanakan tercapai. ${ }^{\text {[2] }}$

Dengan adanya kegiatan pemeliharaan ini, maka mesin/peralatan produksi dapat digunakan sesuai dengan rencana dan tidak mengalami kerusakan selama jangka waktu tertentu yang telah direncanakan tercapai. Tujuan dari kegiatan pemeliharaan dalam dunia industri adalah sebagai berikut: ${ }^{[3]}$

1. Menyelesaikan segala masalah yang berkaitan dengan keberlanjutan proses produksi.

2. Memperpanjang masa pengoperasian segala fasilitas industri.

3. Meminimalisir masa berhentinya proses produksi.

4. Meningkatkan efesiensi sumber daya produksi.

5. Meningkatkan profesionalisme personil bagian perawatan

6. Meningkatkan nilai tambah produk.

7. Membantu para pengambil kebijakan berkaitan dengan pelaksanaan kegitan perawatan.

8. Melakukan perencanaan pelaksanaan kegiatan perawatan yang efektif, dan efisien baik secara teknis maupun secara ekonomis.

9. Mengurangi biaya perawatan termasuk biaya yang timbul akibat berhentinya proses produksi.

\section{Failure Mode and Effect Analysis}

Failure Mode and Effect Analysis (FMEA) adalah teknik rekayasa yang digunakan untuk mendefinisikan, mengidentifikasi, dan menghilangkan kegagalan, masalah, kesalahan, dan sebagainya yang diketahui dan/atau potensial dari sistem, desain, proses, dan/atau layanan. Ada tiga aspek yang membantu menentukan prioritas kegagalan: ${ }^{[4]}$

1.Occurrence adalah frekuensi/tingkat kegagalan.

2.Severity adalah keseriusan (efek) dari kegagalan.

3.Detection adalah kemampuan untuk mendeteksi kegagalan

Tabel 1 Tingkat Kejadian

\begin{tabular}{|c|c|c|}
\hline Probabilitas Kejadian Risiko & Deskripsi & Rating \\
\hline Sangat Tinggi & Sering terjadi & 10 \\
\hline \multirow{2}{*}{ Tinggi } & Terjadi Berulang & 9 \\
\cline { 3 - 3 } & & 8 \\
\hline \multirow{2}{*}{ Sedang } & Jarang Terjadi & 7 \\
\cline { 3 - 3 } & & 5 \\
\hline Rendah & Sangat kecil Terjadi & 4 \\
\cline { 3 - 3 } & Hampir Tidak Pernah Terjadi & 2 \\
\hline Sangat rendah & & 1 \\
\hline
\end{tabular}

Tabel 2 Tingkat Keparahan

\begin{tabular}{|c|c|c|}
\hline Tingkat Keparahan & Tingkat Keparahan Dampak & Rating \\
\hline $\begin{array}{c}\text { Berbahaya tanpa } \\
\text { peringatan }\end{array}$ & Tidak berfungsi sama sekali & 10 \\
\hline $\begin{array}{c}\text { Berbahaya dengan } \\
\text { peringatan }\end{array}$ & Kehilangan fungsi utama dan menimbulkan \\
peringatan & 9 \\
\hline Sangat Tinggi & Kehilangan fungsi utama & 8 \\
\hline Tinggi & Pengurangan fungsi utama & 7 \\
\hline Sedang & Mengurangi kenyamanan fungsi pengguna & 5 \\
\hline Rendah & & \\
\hline
\end{tabular}




\begin{tabular}{|c|c|c|}
\hline Sangat rendah & $\begin{array}{c}\text { Perubahan fungsi dan banyak pekerja } \\
\text { menyadari adanya masalah }\end{array}$ & 4 \\
\hline Minor & $\begin{array}{c}\text { Tidak terdapat efek dan pekerja menyadari } \\
\text { adanya masalah }\end{array}$ & 2 \\
\hline Sangat Minor & $\begin{array}{c}\text { Tidak terdapat efek dan pekerja tidak } \\
\text { menyadari adanya masalah }\end{array}$ \\
\hline Tidak ada & Tidak ada efek & 1 \\
\hline
\end{tabular}

Tabel 3 Tingkat Deteksi

\begin{tabular}{|c|c|c|}
\hline Deteksi & Kemungkinan Deteksi & Rating \\
\hline $\begin{array}{c}\text { Hampir tidak } \\
\text { mungkin }\end{array}$ & Tidak mampu terdeteksi & 10 \\
\hline Sangat jarang & Kesempatan yang sangat rendah dan sangat \\
sulit untuk terdeteksi & 9 \\
\hline Jarang & $\begin{array}{c}\text { Kesempatan yang sangat rendah dan sulit } \\
\text { untuk mendeteksi bentuk penyebab kegagalan } \\
\text { terdeteksi }\end{array}$ & 7 \\
\hline Sangat rendah & Kesempatan yang sangat rendah untuk & 6 \\
\hline Rendah & Kesempatan yang sedang rendah untuk \\
\hline tedang & Kesempatan yang sedang untuk terdeteksi & 5 \\
\hline Agak tinggi & Kesempatan yang cukup tinggi untuk \\
terdeteksi & 4 \\
\hline Tinggi & Kesempatan yang tinggi untuk terdeteksi & 3 \\
\hline Sangat Tinggi & Kesempatan yang sangat tinggi untuk \\
\hline Pasti Terdeteksi & Pasti terdeteksi & 1 \\
\hline
\end{tabular}

Setelah pemberian nilai pada setiap aspek dilakukan, setiap nilai akan dikalikan sehingga diperoleh nilai risk priority number. Nilai tersebut digunakan untuk membandingkan penyebab-penyebab yang teridentifikasi selama dilakukan analisis dari setiap potensi masalah. Perhitungan RPN memiliki rumus sebagai berikut: [5]

$$
R P N=\text { occurrence } \times \text { severity } \times \text { detection }
$$

(1)

\section{Root Cause Analysis}

Root cause analysis (RCA) adalah proses desain yang digunakan untuk mengivestigasi dan mengkategorikan akar penyebab dari sebuah peristiwa yang berhubungan dengan keselamatan, lingkungan, kualitas, keandalan, dan impak dari produksi. Secara sederhana, RCA digunakan untuk membantu mengidentifikasi bukan hanya apa dan bagaimana suatu peristiwa terjadinya. Secara umum, kesalahan tidak terjadi begitu saja tetapi dapat kita analisa seperti mengetahui penyebabnya. Mengidentifikasi akar penyebab adalah salah satu kunci untuk menghindari terjadinya kejadian yang sama. ${ }^{[6]}$

\section{Reliability Block Diagram}

Reliability block diagram (RBD) adalah model logika simbolis mundur (top-down) yang dihasilkan dalam domain sukses. Setiap RBD memiliki input dan output dan mengalir dari kiri ke kanan dari input ke output. Blok dapat menggambarkan peristiwa atau fungsi elemen sistem dalam suatu sistem. Namun, blokblok ini biasanya hanya fungsi elemen sistem. Elemen sistem dapat menjadi subsistem, subassembly, komponen, atau bagian [7]. 
Menurut [8] untuk menghitung keandalan maka yang harus dilakukan adalah mengetahui nilai dari mean time between failure (MTBF) dan nilai failure rate.

1. Mean time between failure (MTBF)

Mean time between failure MTBF adalah ukuran yang menunjukkan berapa lama mesin/komponen dapat beroperasi tanpa mengalami kerusakan atau kegagalan. MTBF juga dapat diartikan sebagai total waktu operasi dibagi jumlah kerusakan ${ }^{[9]}$. Rumus menghitung MTBF adalah sebagai berikut :

$$
M T B F=\frac{\text { operating Time }}{\text { Failure }}
$$

2. Laju kegagalan (failure rate)

Laju kegagalan adalah probabilitas terjadinya kegagalan per satuan waktu dalam sebuah interval waktu. Dimana interval ini disebut juga sebagai MTBF. Adapun rumus untuk menghitung laju kegagalan adalah sebagai berikut :

$$
\lambda=\frac{1}{M T B F}
$$

Setelah didapat nilai MTBF dan failure rate maka dihitung nilai reliability (keandalan) menggunakan rumus sebagai berikut:

$$
R=e^{-((\lambda)(\mathrm{t}))}
$$

Dimana:

$\mathrm{R}=$ Keandalan

$\mathrm{e} \approx 2,71828182846$

$\lambda=$ lambda

$\mathrm{t}=$ asumsi waktu operasi mesin

\section{METODOLOGI PENELITIAN}

Penelitian dilakukan di PMKS PT. Samudera Sawit Nabati yang berlokasi di desa Singgersing,Sultan Daulat,Kota Subulussalam, Aceh 24782 pada tanggal 29 Maret-10 April 2021. Objek yang diteliti adalah mesin screw press yang berada di PT. Samudera Sawit Nabati, Kota Subulussalam. Data yang terkumpul diolah dengan identifikasi kegagalan menggunakan metode Failure Mode and Effect Analysis (FMEA) dan Fault Tree Analysis (FTA) kemudian dihitung keandalannya dengan Reliability Block Diagram (RBD).

\section{HASIL}

\section{FMEA}

Sebelum membuat tabel FMEA terlebih dahulu harus memiliki data historis sebagai acuan untuk mengarahkan untuk mengetahui dasar dari kerusakan, akibatnya terhadap sistem, dan dampaknya terhadap keseluruhan sistem. Setelah dilakukan observasi/pengamatan maka didapat kegagalan-kegagalan yang ada

\begin{tabular}{|c|c|c|c|c|c|c|c|}
\hline No. & Komponen & Kegagalan fungsional & Efek Kegagalan & Sev & Occ & Det & RPN \\
\hline 1 & $\begin{array}{l}\text { Worm } \\
\text { Screw }\end{array}$ & $\begin{array}{c}\text { Tidak dapat } \\
\text { mengektraksi minyak } \\
\text { buah dengan optimal }\end{array}$ & Oil losses tinggi & 4 & 4 & 4 & 64 \\
\hline 2 & Press Cage & $\begin{array}{c}\text { Tidak dapat } \\
\text { menyaring minyak } \\
\text { dengan optimal }\end{array}$ & $\begin{array}{l}\text { Oil losses tinggi } \\
\text { dan terjadi } \\
\text { kebocoran pada } \\
\text { press cage }\end{array}$ & 4 & 3 & 5 & 60 \\
\hline 3 & Oil Seal & $\begin{array}{l}\text { Terjadi kebocoran } \\
\text { oil/pelumas }\end{array}$ & $\begin{array}{l}\text { Mesin beroperasi } \\
\text { tidak optimal }\end{array}$ & 5 & 7 & 6 & 210 \\
\hline 4 & $\begin{array}{l}\text { Thrust } \\
\text { Bearing }\end{array}$ & $\begin{array}{l}\text { Tidak dapat menahan } \\
\text { dan menumpu putaran } \\
\text { shaft secara normal }\end{array}$ & $\begin{array}{c}\text { Mesin tidak } \\
\text { dapat beroperasi }\end{array}$ & 8 & 5 & 6 & 240 \\
\hline 5 & $\begin{array}{l}\text { Roller } \\
\text { Bearing }\end{array}$ & $\begin{array}{l}\text { Tidak dapat menahan } \\
\text { dan menumpu putaran } \\
\text { shaft secara normal }\end{array}$ & $\begin{array}{c}\text { Mesin tidak } \\
\text { dapat beroperasi }\end{array}$ & 8 & 5 & 6 & 240 \\
\hline
\end{tabular}
pada mesin screw press seperti yang ditunjukkan pada Tabel di bawah ini.

Tabel 4 FMEA Mesin Screw Press 


\begin{tabular}{|c|c|c|c|c|c|c|}
\hline Main Shaft & $\begin{array}{c}\text { Tidak dapat } \\
\text { meneruskan putaran }\end{array}$ & $\begin{array}{c}\text { Mesin tidak } \\
\text { dapat beroperasi }\end{array}$ & 9 & 1 & 7 & 63 \\
\hline
\end{tabular}

Melalui tabel FMEA diatas, dapat diketahui komponen pada screw press yang dominan menyebabkan kerusakan pada sistem screw press adalah Thrust Bearing, Roller Bearing, dan Oil Seal dengan masingmasing nilai RPN sebesar 240, 240, dan 210, maka perlu perbaikan yang lebih diprioritaskan pada ketiga komponen tersebut.

\section{Root Cause Analysis}

Identifikasi root cause analysis dari kegagalan pada sistem screw press dapat dilakukan dengan metode “diagram tulang ikan” atau Fish Bone Diagram. Diagram tulang ikan mengidentifikasi penyebab kegagalan berdasarkan 4 kategori yaitu manusia, mesin, metode dan lingkungan seperti yang ditunjukkan pada gambar berikut.

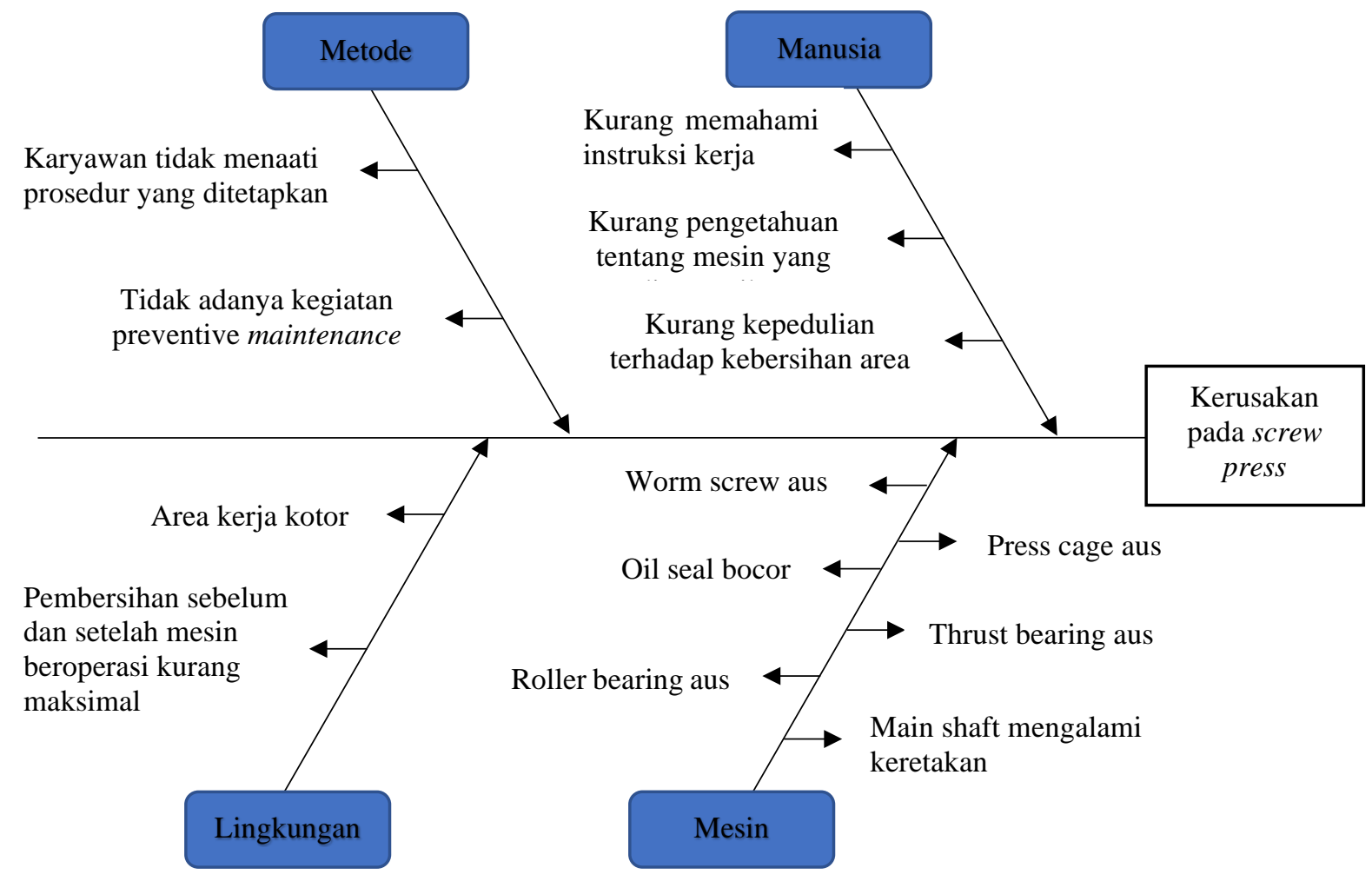

Gambar 1 Fishbone diagram mesin screw press

\section{Reliability Block Diagram}

Perhitungan keandalan sistem pada mesin screw press dilakukan berdasarkan jam operasi dan keseluruhan komponen yang mengalami kerusakan pada screw press. Untuk menghitung keandalan komponen mesin screw press, penulis mengambil asumsi berdasarkan setelah mesin bekerja pada 50, 100, 200, 400, dan 600 jam. Di bawah ini merupakan laju kegagalan dari komponen-komponen mesin screw press serta laju kegagalan sistem yang disusun secara seri yang ditunjukkan pada Tabel 4.28.

Tabel 5 Laju Kegagalan Komponen Screw press

\begin{tabular}{|c|c|c|}
\hline No. & Komponen & Laju Kegagalan $(\lambda)$ \\
\hline 1 & Worm screw & 0,00077 \\
\hline 2 & Press cage & 0,00039 \\
\hline 3 & Oil seal & 0,0015 \\
\hline 4 & Thrust bearing & 0,00077 \\
\hline 5 & Roller bearing & 0,00077 \\
\hline
\end{tabular}




\begin{tabular}{|c|c|c|}
\hline 6 & Main shaft & 0,00039 \\
\hline \multicolumn{2}{|c|}{$\lambda$ Sistem } & 0,00459 \\
\hline
\end{tabular}

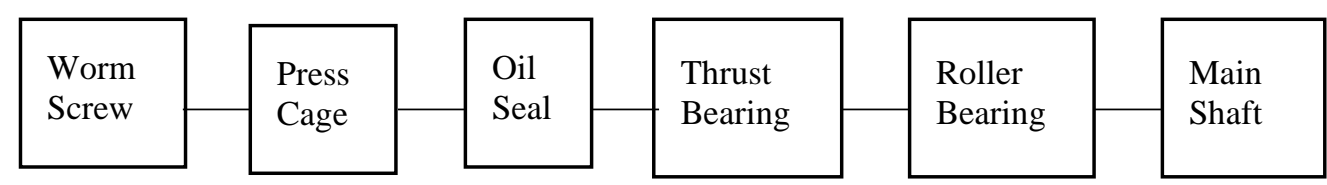

Gambar 2 Rangkaian seri reliability mesin screw press

Keandalan mesin screw press pada 50 jam setelah mesin bekerja adalah sebagai berikut:

$\lambda$ sistem $=0,00459$

Rsistem $=e^{-((\lambda \text { sistem })(\mathrm{t}))}$

Rsistem $=e^{-((0,00459)(50))}$

Rsistem $=0,7949$

Rsistem $=79,49 \%$

Kemudian nilai keandalan mesin screw press pada waktu operasi lainnya dapat dilihat pada Tabel di bawah ini.

Tabel 6 Keandalan mesin screw press

\begin{tabular}{|c|c|c|}
\hline No. & Waktu Operasi & Keandalan \\
\hline $\mathbf{1}$ & $\mathbf{5 0}$ & $\mathbf{7 9 , 4 9} \%$ \\
\hline 2 & 100 & $63,19 \%$ \\
\hline 3 & 200 & $39,93 \%$ \\
\hline 4 & 400 & $15,95 \%$ \\
\hline 5 & 600 & $6,36 \%$ \\
\hline
\end{tabular}

Pada penelitian ini didapat keandalan mesin screw press sebesar 79,49\% setelah 50 jam beroperasi, 63,19\% setelah 100 jam operasi, dan menurun hingga 6,36\% setelah 600 jam operasi.

Mesin atau komponen masih dapat berfungsi dengan baik pada batas keandalan minimum yaitu 0,7 sesuai dengan ketetapan Standar Industri Indonesia (SII) [10]. Sehingga keandalan mesin screw press pada penelitian ini harus dijaga agar keandalannya selalu di atas 70\% dengan melakukan tindakan preventive maintenance setelah mesin beroperasi 50 jam.

\section{KESIMPULAN}

- Komponen pada mesin screw press yang dominan menyebabkan kerusakan pada mesin screw press adalah thrust bearing, roller bearing, dan oil seal dengan masing-masing nilai RPN sebesar 240, 240, dan 210.

- Empat kategori yang menyebabkan kegagalan pada mesin screw press berdasarkan fish bone diagram adalah manusia, mesin, metode, dan lingkungan.

- Nilai keandalan mesin screw press menggunakan reliablity block diagram didapat sebesar 79,49\% setelah digunakan 50 jam. Maka tindakan preventive maintenance yang dilakukan agar keandalan terjaga pada $\geq 70 \%$ adalah pemeriksaan getaran dan bunyi pada bearing serta pemeriksaan visual pada oil seal secara periodik setelah mesin beroperasi 50 jam atau 2 kali siklus produksi.

\section{DAFTAR PUSTAKA}

[1] N. Manurung, N. Firdaus and B. T. Prasetyo, "Reliability Analysis Of Repairable System: Screw Press Machines," Jurnal Momentum, pp. 56-64, 2017. 
[2] A. S. Lesmana, Jaenuddin and T. Rully, "Analisis Pelaksanaan Pemeliharaan Mesin Guna Meningkatkan Efisiensi Biaya Pemeliharaan pada PT Cidas Supra Metalindo," Jurnal Online Mahasiswa Universitas Pakuan, pp. 1-14, 2020.

[3] M. Arsyad and A. Z. Sultan, Manajemen Perawatan, Yogyakarta: Deepiblish, 2018.

[4] D. H. Stamatis, Failure mode and effect analysis:FMEA from theory execution, Milwaukee: American Society for Quality, Quality Press, 2003.

[5] M. Ben-Daya, S. O. Duffua, A. Raouf, J. Knezevic and D. Ait-Kadi, Handbook of Maintenance Management and Engineering, London: Springer-Verlag London Ltd., 2009.

[6] M. D. Amperajaya and Daryanto, "Identifikasi Penyebab Cacat Pulley Pada Proses Pengecoran Di PT. Himalaya Nabeya Indonesia Dengan Metode FMEA \& RCA," Jurnal Inovisi, pp. 1-24, 2007.

[7] B. E. Goldberg, K. Everhart, R. Stevens, N. Babbitt, P. Clemens and L. Stout, System engineering toolbox for design-oriented engineers, Alabama: Marshall Space Flight Center , 1994.

[8] R. Gulati, Maintenance and Reliability Best Practices, New York: Industrial Press, Inc, 2009.

[9] N. Shivananda, World Class Maintenance Management, New Delhi: McGraw Hill Education (India) Ltd, 2015.

[10] D. R. .. Saputra, Y. Sukmono and L. D. Fathimahhayati, "Analisis Reliability Pada Mesin Fan Mill Unit 1 Di PT. Cahaya Fajar Kaltim," DINAMIKA Jurnal Ilmiah Teknik Mesin , pp. 1-8, 2018. 